Document downloaded from:

http://hdl.handle.net/10251/99713

This paper must be cited as:

Pardo-Domenech, L.; Tifrea, A.; Grigore, M.; Boscaiu, M.; Vicente, O. (2016). Proline and glycine betaine accumulation in two succulent halophytes under natural and experimental conditions. Plant Biosystems - An International Journal Dealing with all Aspects of Plant Biology. 150(5):904-915. doi:10.1080/11263504.2014.990943

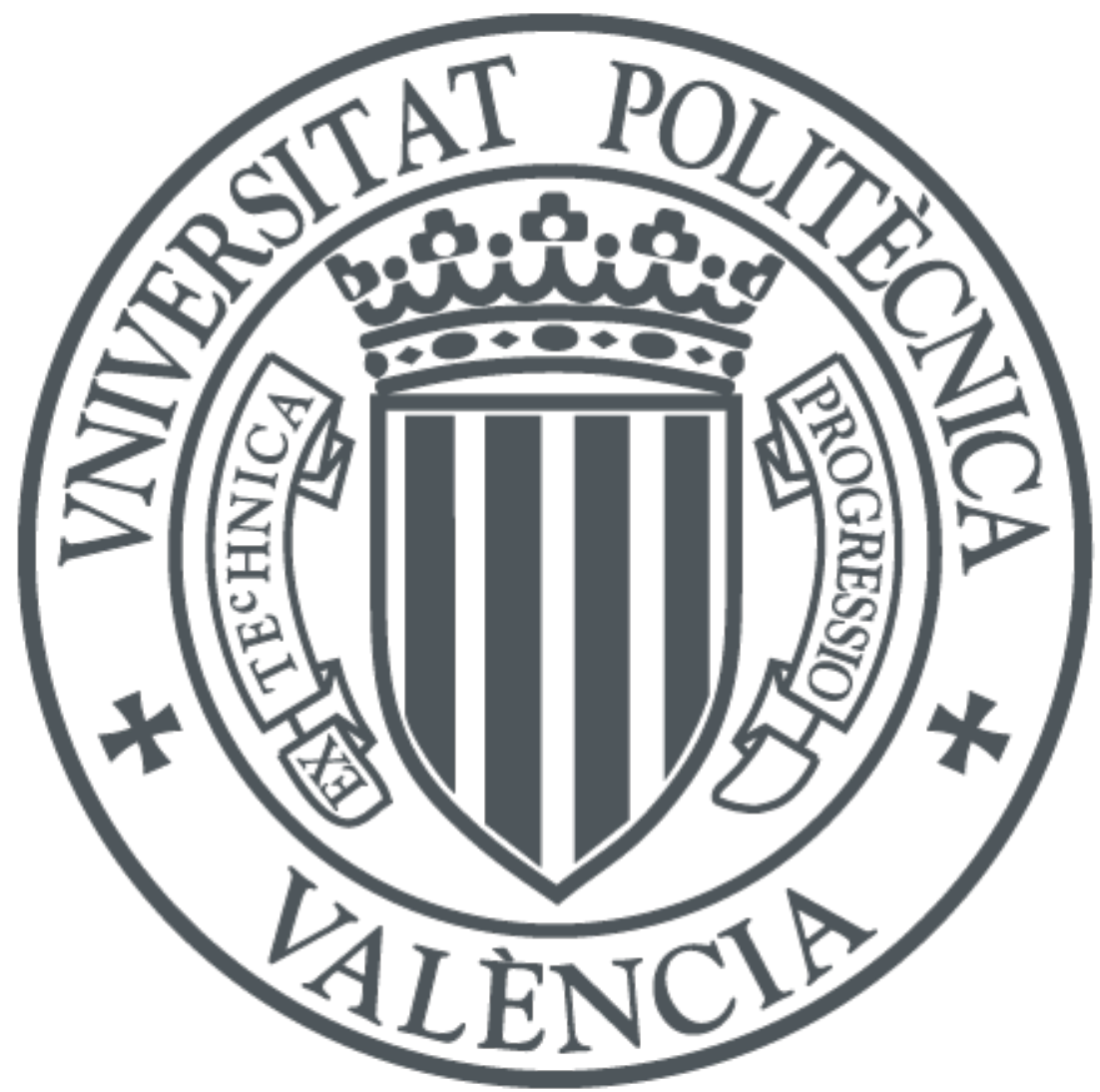

The final publication is available at

https://doi.org/10.1080/11263504.2014.990943

Copyright Taylor \& Francis

Additional Information 


\section{Proline and glycine betaine accumulation in two succulent halophytes under natural and experimental conditions}

Laia L. Pardo-Domènech ${ }^{1}$, Alina Tifrea ${ }^{1,3}$, Marius N. Grigore ${ }^{1,4}$, Monica Boscaiu ${ }^{2}$ and Oscar Vicente ${ }^{1, *}$

${ }^{1}$ Instituto de Biología Molecular y Celular de Plantas (IBMCP, UPV-CSIC), Universitat

Politècnica de València, Camino de Vera s/n, 46022 Valencia (Spain),

eclipse_de_lluna@yahoo.es

${ }^{2}$ Instituto Agroforestal Mediterráneo(IAM, UPV), Universitat Politècnica de València, Camino de Vera s/n, 46022 Valencia (Spain), mobosnea@eaf.upv.es

${ }^{3}$ Permanent address: University of Agricultural Sciences and Veterinary Medicine, Faculty of Horticulture, 3-5 Manastur Str., 400372 Cluj-Napoca, Romania, tifrea.alina@yahoo.com

${ }^{4}$ Permanent address: Alexandru Ioan Cuza University, Faculty of Biology, Carol I, 20 A,

700505 Iasi, Romania, mariusgrigorepsyche@yahoo.com

*Corresponding author, e-mail: ovicente@ibmcp.upv.es

\section{Acknowledgements}

This work was funded by a grant to O.V. from the Spanish Ministry of Science and Innovation (Project CGL2008-00438/BOS), with contribution from the European Regional Development Fund. M.N.G. acknowledges the support provided by COST Action FA0901: 'Putting Halophytes to work - From Genes to Ecosystems' for his stay in Valencia within the frame of a Short-Term Scientific Mission. A.T. acknowledges the Erasmus fellowship programme for funding her stay in Valencia to carry out her Master Thesis.

\section{Disclosure Statement}

The authors declare that there is no conflict of interests regarding the publication of this paper.

Total words number: 7071 


\begin{abstract}
Proline and glycine betaine contents were determined in two Mediterranean halophytes, Plantago crassifolia and Inula crithmoides, to assess their possible role in salt tolerance of both taxa. Plant material was collected in a littoral salt marsh under different environmental conditions, and from plants subjected to salt treatments in a growth chamber. Relative growth inhibition by $\mathrm{NaCl}$ indicated that $I$. crithmoides is more salt-tolerant than $P$. crassifolia, in agreement with the distribution of the two species in nature. Field and laboratory data confirmed glycine betaine as the major osmolyte responsible for osmotic adjustment in I. crithmoides, but with only a minor role -if any-as 'osmoprotectant' in the salt tolerance of $P$. crassifolia. Under natural conditions, proline contents were very low in both taxa, but increased to levels high enough to contribute significantly to osmotic balance when plants were artificially treated with $450-600 \mathrm{mM} \mathrm{NaCl}$ - higher salt concentrations than those they would normally encounter in their natural habitats. These data suggest that halophytes possess built-in mechanisms, such as accumulation of additional osmolytes, to rapidly adapt to increasing salinity levels in their natural ecosystems; for example, those expected to be caused by climate change in salt marshes in the Mediterranean region.
\end{abstract}

Key words: Plantago crassifolia, Inula crithmoides, climate change, osmolytes, salt stress, salt tolerance

\title{
Introduction
}

Salinity is one of the most important environmental stress factors that reduces crop yields worldwide and influences the distribution of wild plants in nature (Boyer 1982; Flowers et al. 1997; Bartels and Sunkar 2005; Munns and Tester 2008). Most angiosperms, including all major crops, are salt-sensitive plants, or glycopyhtes. However, there are some plants that have naturally adapted to saline environments, and are able to survive and complete their life cycle in habitats with a soil salinity equivalent to at least $200 \mathrm{mM} \mathrm{NaCl}$; these species are considered halophytes (Flowers et al. 1986; Flowers and Colmer 2008). They represent only $0.25 \%$ of the total number of angiosperm taxa; that is, about 600 species belonging to different genera and families (Flowers et al. 2010). Halophytes have received the attention of scientists for a number of reasons, including the complex taxonomy of some genera (Kadereit et al. 2007; de la Fuente et al. 2013), their ecological interest (Boorman 2003; Biondi et al. 2013; Eliáš et al. 2013), or their practical use in agriculture (Glenn et al. 1999; Rozema and Flowers 2008). Halophytes are also appropriate models to investigate abiotic stress tolerance in plants, through the understanding of the mechanisms which allow them to survive in the harsh conditions of saline ecosystems, which cover a variety of wet and dry environments, such as estuaries and other coastal areas, littoral and inland salt marshes, salt deserts, dunes or cliffs by the sea. 
Halophytes may show diverse morphological, anatomical, physiological and biochemical adaptations to high salinity, but the present study centres on one basic, conserved mechanism of response to salt stress; namely, biosynthesis and cellular accumulation of osmolytes. Osmolytes are 'compatible solutes' that can reach very high cellular concentrations without interfering with normal plant metabolism. They appear to play a major role in osmotic adjustment in all environmental conditions leading to cellular dehydration, including salt stress (Flowers and Colmer 2008). In addition, osmolytes can also act as 'osmoprotectants': they function as low-molecular-weight chaperons that help stabilise proteins and macromolecular cellular structures under stress conditions, and as ROS scavengers that protect the cells from oxidative stress (Ashraf 2009; Cushman 2001). These additional roles reinforce the importance of compatible solutes in salt tolerance mechanisms, to which osmolytes may contribute even if they do not accumulate to high intracellular concentrations and have no significant effect on osmotic adjustment. However, these multiple functions of osmolytes also complicate the analysis of their mechanisms of action in responses of plants to salt stress (Gil et al. 2013).

One of the commonest osmolytes in plants is proline (Pro), an imino acid that accumulates in the cytosol of many higher plants in response to different abiotic stresses: high salinity, drought, cold, high temperature, nutritional deficiencies, heavy metals, air pollution, or high UV radiation (Saradhi et al. 1995; Hare and Cress 1997; Siripornadulsil et al. 2002; Grigore et al. 2011). Pro may substantially contribute to cytoplasmic osmotic adjustment if accumulated at a sufficiently high concentration, but several other functions as an osmoprotectant have been described for Pro, which should not require such high contents. Thus, Pro directly stabilises proteins, membranes and other subcellular structures (Verbruggen and Hermans 2008), and also contributes to scavenge free radicals and to balance the cell redox status under stress conditions (Smirnoff and Cumbes 1989; Verbruggen and Hermans 2008). Pro may also function as a hydrotrope by relieving the cytoplasmic acidosis and maintaining a $\mathrm{NADP}^{+}$/ NADPH ratio that is compatible with the metabolism (Hare and Cress 1997; Ksouri et al. 2010). Moreover, Pro can also be considered a molecule for the storage of carbon and nitrogen during stress, which will help the recovery of tissues when stress eases or disappears (Hare and Cress 1997; Szabados and Savouré 2010). Its rapid degradation can provide sufficient reducing agents that enhance mitochondrial oxidative phosphorylation and ATP generation to repair any damage induced by stress.

Glycine betaine (GB) is a quaternary ammonium compound that accumulates in response to salt and water stress in many different organisms. In angiosperms, the synthesis of glycine betaine occurs in chloroplasts from serine via ethanolamine, choline and beta-aldehyde (Hanson and Scott 1980; Rhodes and Hanson 1993; Ashraf and Foolad 2007). Therefore it is abundant in chloroplasts, where it plays a fundamental role in the protection of the thylakoid membrane to maintain photosynthetic efficiency (Robinson and Jones 1986; Genard et al. 1991, 
Ashraf and Foolad 2007). In addition to its osmotic effects and direct protective roles as an osmoprotectant, glycine betaine seems to contribute indirectly to salt stress tolerance by improving stomatal conductance, its implication in ionic homeostasis, and by helping in $\mathrm{K}^{+} / \mathrm{Na}^{+}$ discrimination or, more generally, via its function as a signalling molecule to activate the expression of different genes (Chen and Murata 2008, 2011; Nawaz and Ashraf 2010).

There are many published reports on the accumulation in halophytes of Pro or GB -as well as of other osmolytes, such as soluble sugars and polyalcohols (Gil et al. 2013)- as a response to salt stress under controlled, but artificial, laboratory or greenhouse conditions. However, very few field studies that correlate osmolyte contents and the degree of environmental stress affecting plants in their natural habitats have been carried out. Consequently, the biological and ecological relevance of osmolyte accumulation and the relative contribution of different osmolytes to salt tolerance in a given halophytic species, remain largely unknown.

The aim of the present work was to assess the role of Pro and GB, as functional osmolytes, in the salt tolerance mechanisms of two succulent halophytes, Plantago crassifolia (Plantaginaceae) and Inula crithmoides (Asteraceae). Sorbitol has been reported as the main osmolyte in several Plantago species (Ahmad et al. 1979, Koyro 2006); in P. crassifolia, seasonal changes in sorbitol levels were detected in the field (Gil et al. 2011), but salt treatments under controlled greenhouse conditions also led to a significant increase of proline contents (Vicente et al. 2004). Regarding the second species under study, I. crithmoides, there is only one previous publication reporting the presence of GB in this and other coastal plants (AdrianRomero et al. 1998), but without addressing possible fluctuations in the levels of the osmolyte in response to changing environmental stress factors.

We have analysed the accumulation of both, Pro and GB, in plant material of $P$. crassifolia and I. crithmoides collected in the field in six successive samplings, over a 2-year period (2009 and 2010), and then correlated changes in osmolyte contents with the intensity of environmental stress affecting the plants, estimated from soil analyses and recorded meteorological data. Although this approach is relatively novel, as mentioned above, we are aware that field data are not easily interpreted, since plants are simultaneously affected by different environmental stress conditions: soil salinity, water deficit, high temperatures, UV radiation, etc., which can all induce osmolyte biosynthesis. Therefore, to complement work with plants collected in their natural habitat, the effects of controlled salt treatments on plants of the same species, in growth inhibition and osmolyte accumulation terms were also analysed.

\section{Material and Methods}

\section{Plant species}


The species under study are common halophytes throughout the Mediterranean region and present in littoral salt marshes in SE SpainBoth are perennial, succulent taxa; I. crithmoides is a shrub that grows up to $1 \mathrm{~m}$ high, while $P$. crassifolia is a rhizomatous hemicryptophyte measuring $6-30 \mathrm{~cm}$.

\section{Experimental design}

Proline (Pro) and glycine betaine (GB) levels were determined in I. crithmoides and $P$. crassifolia plants growing in two nearby plots defined in a littoral salt marsh in the 'La Albufera' Natural Park (39 $21^{\circ}$ N, $0^{\circ} 19^{\prime}$ W) near the city of Valencia (E Spain). I. crithmoides is present in the central, most depressed wet part of the salt marsh, where soil salinity is maximal, whereas P. crassifolia was sampled from the sandy and less saline border of the salt marsh. Pro and GB contents were also measured in 3-month old potted plants of both species, obtained by germination of seeds (collected in the same salt marsh), treated for 2 months with different $\mathrm{NaCl}$ concentrations in a growth chamber.

\section{Climate and soil analysis}

Climatic conditions were assessed on the basis of weekly data of mean temperatures, rainfall, and evapotranspiration (ETP) registered by the nearest agroclimatological station, located about $10 \mathrm{~km}$ from the experimental zone, during the 2 months previous to each sampling of plant and soil material; the data were provided by the Agroclimatic Information System for Irrigation (SIAR) of the Spanish Ministry of Environment, Rural and Marine Affairs (MARM). Soil electric conductivity (EC) was analysed in three soil samples randomly taken, from a depth of 0-15 cm, in the each of the sampling areas of P. crassifolia (Plot 1) and I. crithmoides (Plot 2), simultaneously with collection of the plant material. Electric conductivity was measured in soil aqueous extracts at a soil-to-water ratio of 1:1 (w/v) $\left(\mathrm{EC}_{1: 1}\right)$ using a Crison 522 conductivimeter. The same method was used to analyse the $\mathrm{EC}_{1: 1}$ of the substrate in the pots at the end of the $\mathrm{NaCl}$ treatments in the growth chamber.

\section{Plant material and salt treatments}

Leaf material was independently collected in the field from five individual plants of each species, cooled on ice and then transported to the laboratory where, after weighing on a precision balance, part of each sample was frozen and stored at $-80^{\circ} \mathrm{C}$ for further analysis. The remaining material was dried at $65^{\circ} \mathrm{C}$ until constant weight to calculate the relation dry weight (DW) / fresh weight (FW) for each plant. Sampling from the same individuals, which were marked in the field at the time of the first sample collection, was repeated six times over a 20month period from spring 2009 to autumn 2010.

Seeds of both species were collected in summer 2010 in the plants' natural habitat and were stored for 3 months at room temperature. Sowing was carried out on a mixture of peat and 
vermiculite (3:1), and seedlings were transferred to individual $9 \mathrm{~cm}$-diameter pots on the same substrate 1 month after emergence.

Plants were grown in a growth chamber (Infraca) equipped with three Master TL-D 58W fluorescent lamps (Philips) per shelf, which provided $150 \mu \mathrm{E} \mathrm{m}^{-2} \mathrm{~s}^{-1} \mathrm{PAR}$, under a photoperiod of $12 \mathrm{~h} \mathrm{light}$ and $12 \mathrm{~h}$ darkness, at $25^{\circ} \mathrm{C}$ and $15^{\circ} \mathrm{C}$, respectively.

Salt treatments were applied to five individuals per species and per treatment by watering the pots weekly with $150 \mathrm{ml}$ of $\mathrm{NaCl}$ solutions of increasing concentrations: 150,300 , 450 and $600 \mathrm{mM}$ (or with water, for the non-stressed controls). After 2 months, plants were sampled and aerial parts weighed on a precision balance. The length of the stem in Inula crithmoides, and that of the longest leaf in Plantago crassifolia (which produces only rosette leaves and floral scapes) were measured, and samples were frozen and stored at $-80^{\circ} \mathrm{C}$.

\section{Osmolyte quantification}

Frozen plant material $(250 \mathrm{mg})$, collected in the field or from the plants grown in the growth chamber, was ground to a fine powder in a mortar in the presence of liquid nitrogen, and Pro content was determined according to the method of Bates et al. (1973) with minor modifications, as described in Vicente et al. (2004). The extraction and quantification of glycine betaine was performed following the method of Grieve and Grattan (1983) with the modifications proposed by Nawaz and Ashraf (2010). Osmolyte levels referred to the FW of the corresponding sample, and were expressed as $\mu \mathrm{mol} \mathrm{g}{ }^{-1}$ of FW. For the field-collected material, Pro and GB contents were also calculated as $\mu \mathrm{mol}$ per gram of DW.

\section{Statistical analysis}

Data were analysed using the SPSS programme for Windows, v.16.00. Prior to the analysis, the Levene test was applied to check the ANOVA requirements. The plant growth data were transformed into percentages. The significance of differences between treatments and seasons were assessed using one-way ANOVA and the Tukey test was used for the post hoc analysis.

\section{Results}

\section{Climate and soil analysis}

As expected for the Mediterranean climate, summers (2009 and 2010) were the most stressful periods (Rivas-Martínez and Rivas-Sáenz 2009), with the highest temperature and evapotranspiration (ETP), and the lowest precipitation, although summer 2010 was not as dry as summer 2009. Spring 2010 was the mildest season, with low ETP, cool temperatures and considerable rain (Table 1). 
Soil electric conductivity was higher in the sampling area of I. crithmodes than in that of P. crassifolia, which grew only in the zones of the salt marsh with lower EC (Fig. 1a).

Regarding seasonal fluctuations of soil salinity, as reflected by EC measurements in both areas, the highest values were registered in summer, especially in the first year, 2009. The high ETP in this season causes an upward movement of water with dissolved salts that accumulate in the soil surface, thus explaining a significant increase of the soil EC.

Electric conductivity in the pots at the end of the salt treatments surpassed by far the values registered in the field (Fig. 1b), reaching values 4.5 -fold higher than those measured in summer 2009 in the more saline plot 2, where I. crithmoides grows, and more than 18-fold higher as compared to the highest values in plot 1 , were $P$. crassifolia is present.

\section{Osmolyte levels in plants sampled in their natural habitat}

The Pro contents in Plantago crassifolia plants sampled in the field showed seasonal variations, with the highest values determined in autumn 2010, followed by summer and autumn 2009, but absolute Pro levels were very low, under $0.20 \mu \mathrm{mol} \mathrm{g}^{-1}$ of FW in all the samplings (Fig. 2a). When expressed in DW terms, the Pro accumulation pattern was somewhat different -as expected, since plant water content also varied slightly depending on the sampling period-with the maximum value $\left(1.54 \pm 0.50 \mu \mathrm{mol} \mathrm{g}{ }^{-1}\right.$ of DW) recorded in autumn 2009 (data not shown). In any case, referring to either fresh weight or dry weight, the observed Pro accumulation pattern did not correspond to the degree of environmental stress affecting the plants in the field, because summer 2009, followed by summer 2010, were the most stressful seasons during the study period (Fig. 1a, Table 1).

Regarding GB contents in P. crassifolia, the absolute values were also low, with a maximum of $2.79 \pm 0.41 \mu \mathrm{mol} \mathrm{g}^{-1}$ of FW (Fig. $2 b$ ) or $16.79 \pm 1.31 \mu \mathrm{mol} \mathrm{g}^{-1}$ of DW(data not shown). However, unlike what was observed for Pro, the GB seasonal variation patterns roughly correlated with the degree of environmental stress in the experimental area, with maximum levels in summer 2009 and summer 2010 (Fig. 2b).

The Pro contents in the I. crithmoides plants sampled in the field were also low, and were only slightly higher than those determined in P. crassifolia (Fig. 2c). Seasonal variations in Pro levels correlated partly, at least qualitatively, with the degree of salt and water stress in the salt marsh. The highest mean Pro content was detected in summer 2009, the period with the highest salinity and strongest water deficit, while the lowest mean value was determined in the mildest season, spring 2009 (Fig. 2c; see also Fig. 1a, Table 1). Nevertheless, the data for summer 2010 did not fit this general pattern and most differences were not statistically significant.

A different situation was observed when analysing GB levels in I. crithmoides: mean values, which ranged from approximately 25 to $45 \mu \mathrm{mol} \mathrm{g} \mathrm{g}^{-1}$ of FW (Fig. 1d), were by far higher 
than those of Pro, and were also much higher than those of GB in P. crassifolia. However, no statistically significant differences were found between the GB contents determined in different seasons when expressed in plant FW terms (Fig. 2d). Only when the GB levels referred to plant dry weight did the samples collected in summer 2009 give a significantly higher value (313.29 \pm $75.86 \mu \mathrm{mol} \mathrm{g}{ }^{-1} \mathrm{DW}$ ) as compared to the plant material from all the other samplings. This difference can be easily explained when considering the significant water loss of the $I$. crithmoides plants during this specific period, as reflected in a relatively higher percentage of DW (not shown).

\section{Effect of salt treatments on plant growth}

Under controlled growth chamber conditions, salt stress negatively affected the growth of $P$. crassifolia in a concentration-dependent manner (Fig. 3, black bars). Both the length of the longest leaf of plants (Fig. 3a) and, even more clearly, their FW (Fig. 3b) reduced gradually with increasing $\mathrm{NaCl}$ concentrations after 2 months of salt treatments. Under the most stressful conditions tested $(600 \mathrm{mM} \mathrm{NaCl})$, leaf length and FW reduced by about $20 \%$ and $90 \%$, respectively, as compared to the control non-treated plants.

Growth of I. crithmoides was also inhibited by salt, but only in the presence of high $\mathrm{NaCl}$ concentrations, over $300 \mathrm{mM}$ (Fig. 3, white bars). At a lower salt concentration (150 mM $\mathrm{NaCl}$ ), a stimulation of plant growth was in fact noted as compared with the control plants, and as shown by increased length (Fig. 3a) and FW (Fig. 3b). This is a common behaviour of many highly tolerant dicotyledonous halophytes, which display optimal growth in the presence of low or moderate salinity levels (Flowers et al 1977, and references within).

\section{Osmolyte accumulation upon controlled salt treatments}

The Pro contents in the potted $P$. crassifolia plants treated with up to $300 \mathrm{mM} \mathrm{NaCl}$ were very low, similar to those determined in the field material, and not significantly different from the levels in the control plants (Fig. 4a). At higher salt concentrations, however, a strong Pro accumulation was observed, which reached almost $12 \mu \mathrm{mol} \mathrm{g}{ }^{-1} \mathrm{FW}$ in the presence of $600 \mathrm{mM}$ $\mathrm{NaCl}$, the highest concentration tested; that is, approximately a 70-fold increase as compared to the control plants (Fig. 4a). Regarding GB, a slight increase in the mean levels of this osmolyte, with increasing salt concentrations, was also detected in $P$. crassifolia, but the differences with the control non-treated plants were statistically significant only at $600 \mathrm{mM} \mathrm{NaCl}$ (Fig. 4b). Nevertheless, even under these drastic salt stress conditions, the increase in GB content was somewhat modest, less than 4-fold more than in the non-stressed plant material.

In I. crithmoides, treatments with a salt concentration of $300 \mathrm{mM} \mathrm{NaCl}$ or higher also led to significant Pro accumulation, with maximum values of about $10 \mu \mathrm{mol} \mathrm{g}{ }^{-1} \mathrm{FW}$ (Fig. 4c) in the presence of 450 or $600 \mathrm{mM} \mathrm{NaCl}$, which are similar to those determined in P. crassifolia 
(Fig. 4a); this is a 100-fold increase in Pro content if compared to the control plants. The pattern of $\mathrm{GB}$ accumulation in response to increasing $\mathrm{NaCl}$ concentrations was qualitatively similar to that of Pro, but with higher absolute values (ca. $35 \mu \mathrm{mol} \mathrm{g}{ }^{-1} \mathrm{FW}$ ), reached in the presence of 450 or $600 \mathrm{mM} \mathrm{NaCl}$, which is about 7-fold more than in non-stressed plants (Fig. 3d). The $150 \mathrm{mM}$ $\mathrm{NaCl}$ treatments did not significantly increase the levels of either of the two osmolytes (Fig. 4c, d). This was to be expected since these conditions were optimal for the growth of $I$. crithmoides plants (Fig. 3) and should not be considered 'stressful' for this species.

\section{Discussion}

Osmolyte biosynthesis is a general response of plants, and of all organisms actually, to environmental stress conditions leading to cellular dehydration, such as drought or high salinity. Accumulation of these compatible solutes in the cytoplasm is considered essential for osmotic adjustment in those circumstances (Munns 2002; Flowers and Comer 2008; Munns and Tester 2008; Türkan and Demiral 2009). Proline and glycine betaine are probably the commonest osmolytes in plants, used by many angiosperm species to help maintain cellular osmotic balance. Yet according to our field studies, this was not the case in Plantago crassifolia, where the levels of both compounds were too low to have any significant osmotic effect, not even when assuming that they accumulated exclusively in the relatively small volume of the cytoplasm. This was somewhat expected since the polyalcohol sorbitol, and not amino acids or quaternary ammonium compounds, appears to be the functional osmolyte in all the plants of the genus Plantago, both halophytes and glycophytes (Flowers et al. 2010). This has been shown, for example, for the salt-tolerant P. maritima (Ahmad et al. 1979; Jefferies et al. 1979; Königshofer 1983) and P. coronopus (Gorham et al. 1981; Koyro 2006), and for the saltsensitive $P$. media and $P$. lanceolata (Königshofer 1983). Recent studies have confirmed that $P$. crassifolia is also a sorbitol accumulator like its congener species, and a clear correlation has been found between seasonal changes in sorbitol contents in plants and the degree of environmental stress in their natural habitat (Gil et al. 2011). The fact that Pro and GB do not participate in osmotic adjustment does not rule out the possibility of them playing some role in the salt tolerance mechanisms in $P$. crassifolia based on their additional functions as osmoprotectants: low-molecular-weight chaperons and/or ROS scavengers. GB may indeed provide a minor contribution to salt tolerance in $P$. crassifolia, as suggested by the detection of its highest levels in summer 2009 and 2010, the most stressful sampling seasons. This correlation of osmolyte contents and environmental stress intensity was not observed for Pro, which probably has no effect, not even a minor one, on the salt tolerance mechanisms of this species under field conditions.

In Inula crithmoides GB appears to be the major functional osmolyte as high enough levels accumulate to have substantial effects on osmotic adjustment. The highest GB contents, 
expressed as $\mu \mathrm{mol} / \mathrm{g} \mathrm{DW}$, were detected in the samples collected in summer 2009, when soil salinity and water deficit were at their peak, although in 'fresh weight' terms, seasonal differences were not statistically significant. It seems that the induction of relatively small changes in the osmolyte levels in response to external stress is a general feature of GB accumulators (e.g., Cavalieri 1983; Khan et al. 2000; Katschnig et al. 2013). Our field data also suggest that Pro may play a role, albeit only a secondary one, in I. crithmoides salt tolerance mechanisms, which is unrelated to the maintenance of osmotic balance, but is based on its putative functions as an 'osmoprotectant'.

The relative salt tolerance of different halophytic species is considered the most important factor to influence the distribution of these taxa in their natural saline habitats. According to this criterion, I. crithmoides should be more salt-tolerant than P. crassifolia: the former is a typical plant of the more depressed, humid and saline central part of salt marshes, whereas the latter grows on the sandy borders of the marsh, where soil salinity is not so high. This notion was supported by the relative effects of the salt stress treatments on the growth of both species in the controlled environment of a growth chamber: higher $\mathrm{NaCl}$ concentrations were necessary to inhibit plant growth in I. crithmoides than in P. crassifolia. Slower growth is the most general effect of salt stress, as for other abiotic stresses, and allows plants to re-direct cell resources (i.e., energy and metabolic precursors) towards the activation of defence reactions against stress (Zhu 2001). All glycophytes and most halophytic species grow optimally in the absence of salt. This is the case for $P$. crassifolia, whose vegetative growth progressively reduced with increasing external $\mathrm{NaCl}$ concentrations, as indicated by a significant decrease in the FW of the plants and, to a lesser extent, in the mean length of the longest leaf. These data support and extend previous studies on the influence of salinity on the vegetative development of this species (Vicente et al. 2004). Nonetheless, more recent results indicate that in older plants, salt affects mostly reproductive parameters, such as quantity and quality of flowers and seeds (Grigore et al. 2012). Numerous studies have shown that salt tolerance is developmentally regulated, and the responses to salt stress of a given species may be quite diverse at different life cycle stages (Flowers et al. 1986; Lauchli and Epstein 1990; Johnson et al. 1992; Vicente et al. 2004). Extreme dicotyledonous halophytes, on the contrary, generally show some stimulation of growth at low or moderate salinity levels $(50-250 \mathrm{mM} \mathrm{NaCl})$, although higher salt concentrations still reduce plant growth rates (Flowers et al. 1986). This behaviour has been observed, for example, in species of the genera Salicornia (Grouzis 1973; Grouzis et al. 1977), Sarcocornia (Naidoo and Rughunanan 1990), Suaeda (Flowers 1972; Williams and Ungar 1972; Boucaud and Ungar 1978; Hekmat-Shoar 1978; Yeo and Flowers 1980; Eshel 1985a, b) or Salsola (Xing et al. 2013). Inula crithmoides clearly belongs to this group of highly salttolerant halophytes; in the presence of $150 \mathrm{mM} \mathrm{NaCl}$, the average length and $\mathrm{FW}$ of these plants 
increased to $150 \%$ of the non-treated controls, and growth inhibition was detected only at a salt concentration of $300 \mathrm{mM}$ or higher.

As discussed more extensively elsewhere (Boscaiu et al. 2013; Gil et al. 2013), in general it is not possible to directly compare in quantitative terms field and laboratory data on plant responses to salt stress, such as osmolyte accumulation, for different reasons, including: the impossibility to accurately mimic the environmental conditions of plants' natural habitats in an artificial set-up; their different developmental stages (adult individuals in the field $v s$. seedlings or young plants grown from seeds in a growth chamber or greenhouse); or the restricted physical space available to the root system in potted plants. Nevertheless, the analysis of the changes in osmolytes levels in response to controlled salt treatments supports the conclusions of the field studies conducted on the function(s) of GB in the salt tolerance mechanisms of the investigated species. GB is most likely the major compatible solute in $I$. crithmoides, and is responsible for osmotic adjustment under stress conditions as it accumulates to relatively high levels in the presence of $\mathrm{NaCl}$ at a concentration of $300 \mathrm{mM}$ or higher. However, this osmolyte would play only a secondary role, if any, in salt tolerance of $P$. crassifolia by acting as an 'osmoprotectant', but with no effect on cellular osmotic balance. As mentioned before, the range of variation of GB contents was relatively narrow, even when $I$. crithmoides and $P$. crassifolia were subjected to drastic salt treatments. This agrees with previous reports on GB accumulation in other species, which also showed relatively small increases in GB contents with increasing external salt concentration (Khan et al. 1998, 2000; Katschnig et al. 2013).

The Pro accumulation patterns of the plants treated with $\mathrm{NaCl}$ in the growth chamber differed from those of GB. The Pro levels in both species remained very low, as they did under field conditions, in the presence of low or moderate salinity. However, there was a vast increase in the Pro contents in the plants treated with high salt concentrations $(600 \mathrm{mM} \mathrm{NaCl})$, about 70 fold in P. crassifolia and 100-fold in I. crithmoides, reaching levels that can clearly contribute to cellular osmotic adjustment and, therefore, to salt tolerance. Qualitatively similar results have been previously reported by our group in P. crassifolia - with a ca. 20-fold increase in Pro levels in the presence of $500 \mathrm{mM} \mathrm{NaCl}$, although older plants were used in those experiments (Vicente et al. 2004) - and more recently also in other Plantago taxa, $P$. coronopus and $P$. lagopus (Pacurar et al. 2013), as well as by other authors in many species from other genera and families, starting with early studies by Stewart and Lee (1974).

It should be pointed out that these plants, and especially the less salt-tolerant $P$. crassifolia, are never exposed in their natural habitats to the high salinity levels measured in the pots upon $\mathrm{NaCl}$ treatments in the growth chamber. Therefore, our results suggest that when $P$. crassifolia and I. crithmoides are artificially exposed to very strong salt stress conditions, they can activate the synthesis and accumulation of an additional osmolyte, Pro in this case, which 
will contribute to salt tolerance, but is not used -because it is not needed-under normal conditions in their natural ecosystems. This finding should be important from an ecological point of view, as it could be generalised to other halophytic species and osmolytes or, more generally, to other salt tolerance mechanisms. Littoral salt marshes in the Mediterranean region are extremely sensitive to the effects of climate change: increase in average temperatures; longer, more frequent and more intense drought periods; 'heat waves', etc., which will probably lead to increased soil salinity in the years ahead. It is generally assumed that this will negatively affect the halophytic vegetation of these saline habitats and cause loss in biodiversity. However, if halophytes indeed possess built-in mechanisms to rapidly adapt to increasing salinity, such as accumulation of additional osmolytes, they may be able to withstand these changes in their own ecosystem conditions better than we currently assume.

\section{References}

Adrian-Romero M, Wilson SJ, Blunden G, Yang M, Carabot-Cuervo A, Bashir AK. 1998. Betaines in coastal plants. Biochem Syst Ecol 26: 535-543.

Ahmad I, Larher F, Stewart GR. 1979. Sorbitol, a compatible osmotic solute in Plantago maritima. New Phytol 82: 671-678.

Ashraf MY. 2009. Salt tolerance mechanisms in some halophytes from Saudi Arabia and Egypt. Res J Agric Biol Sci 5: 191-206.

Ashraf MY, Foolad MR. 2007. Roles of glycine betaine and proline in improving plant abiotic stress resistance. Environ Exp Bot 59: 206-216.

Bartels D, Sunkar R. 2005. Drought and salt tolerance in plants. Crit Rev Plant Sci 24: 23-59.

Bates LS, Waldren RP, Tear LD. 1973. Rapid determination of free proline for water-stress studies. Plant Soil 39: 205-207.

Biondi E, Casavecchia S, Estrelles E, Soriano P. 2013. Halocnemum M. Bieb. vegetation in the Mediterranean Basin. Plant Biosyst 147: 536-547.

Boorman LA. 2003. Saltmarsh Review. An overview of coastal saltmarshes, their dynamic and sensitivity characteristics for conservation and management. JNCC Report, No. 334, JNCC, Peterborough.

Boscaiu M, Lull C, Llinares J, Vicente O, Boira H. 2013. Proline as a biochemical marker in relation to the ecology of two halophytic Juncus species. J Plant Ecol 6: 177-186.

Boucaud J, Ungar IA. 1978. Halophile et résistance au sel dans le genre Suaeda Forsk. B Soc Bot Fr 125: 23-35.

Boyer JS. 1982. Plant productivity and environment. Science 218: 443-448.

Cavalieri AJ. 1983. Proline and glycinebetaine accumulation by Spartina alterniflora Loisel. in response to $\mathrm{NaCl}$ and Nitrogen in a controlled environment. Oecologia 57: 20-24. 
Chen THH, Murata N. 2008. Glycinebetaine: an effective protectant against abiotic stress in plants. Trends Plant Sci 13: 499-505.

Chen THH, Murata N. 2011. Glycinebetaine protects plants against abiotic stress: mechanisms and biotechnological applications. Plant Cell Environ 34: 1-20.

Cushman JC. 2001. Osmoregulation in plants: implications for agriculture. Am Zool 41: 758 769.

de la Fuente V, Oggerin M, Rufo L, Rodríguez N, Ortuñez E, Sánchez-Mata D, Amils R. 2013. A micromorphological and phylogenetic study of Sarcocornia A.J. Scott (Chenopodiaceae) on the Iberian Peninsula. Plant Biosyst 147: 158-173.

Eliáš Jun. P, Dítě D, Šuvada R, Píš V, Ikrényi I. 2013. Hordeum geniculatum in the Pannonian Basin: Ecological requirements and grassland vegetation on salt-affected soils. Plant Biosyst 147: 429-444.

Eshel A. 1985a. Response of Suaeda aegyptiaca to $\mathrm{KCl}, \mathrm{NaCl}$ and $\mathrm{Na}_{2} \mathrm{SO}_{4}$ treatments. Physiol Plant 64: 308-315.

Eshel A. 1985b. Effects of $\mathrm{NaCl}$ and $\mathrm{KCl}$ on growth and ionic composition of the halophytic $\mathrm{C}_{4}$ succulent chenopods Salsola kali, Suaeda monoica and Suaeda aegyptiaca. Aust J Plant Physiol 12: 319-328.

Flowers TJ. 1972. Salt tolerance in Suaeda maritima (L). Dum. The effect of sodium chloride on growth, respiration, and soluble enzymes in a comparative study with Pisum sativum L. J Exp Bot 23: 310-321.

Flowers TJ, Colmer TD. 2008. Salinity tolerance in halophytes. New Phytol 179: 945-963.

Flowers TJ, Galal HK, Bromham L. 2010. Evolution of halophytes: multiple origins of salt tolerance in land plants. Funct Plant Biol 37: 604-612.

Flowers TJ, Garcia A, Koyama M, Yeo AR. 1997. Breeding for salt tolerance in crop plants the role of molecular biology. Acta Physiol Plant 19: 427-433.

Flowers TJ, Hajibagheri MA, Clipson NJW. 1986. Halophytes. Q Rev Biol 61: 313-335.

Flowers TJ, Troke PF, Yeo AR. 1977. The mechanism of salt tolerance in halophytes. Ann Rev Plant Physiol 28: 89-121.

Genard H, Le Saos J, Hillard J, Tremolieres A, Boucaud J. 1991. Effect of salinity on lipid composition, glycine betaine content and photosynthetic activity in chloroplasts of Suaeda maritima. Plant Physiol Biochem 29: 421-427.

Gil R, Boscaiu M, Lull C, Bautista I, Lidón A, Vicente O. 2013. Are soluble carbohydrates ecologically relevant for salt tolerance in halophytes? Funct Plant Biol 40: 805-818.

Gil R, Lull C, Boscaiu M, Bautista I, Lidón A, Vicente O. 2011. Soluble carbohydrates as osmolytes in several halophytes from a Mediterranean salt marsh. Not Bot Horti Agrobo 39: 9-17. 
Glenn EP, Brown JJ, Blumwald E. 1999. Salt tolerance and crop potential of halophytes. Crit Rev Plant Sci 18: 227-255.

Gorham J, Hughes LY, Wyn Jones RG. 1981. Low molecular weight carbohydrates in some salt stressed plants. Physiol Plant 53: 27-33.

Grieve C M, Grattan SR. 1983. Rapid assay for determination of water soluble quaternary ammonium compounds. Plant Soil 70: 303-307.

Grigore MN, Boscaiu M, Llinares J, Vicente O. 2012. Mitigation of salt stressed-induced inhibition of Plantago crassifolia reproductive development by supplemental calcium or magnesium. Not Bot Horti Agrobo 40: 58-66.

Grigore MN, Boscaiu M, Vicente O. 2011. Assessment of the relevance of osmolyte biosynthesis for salt tolerance of halophytes under natural conditions. Eur J Plant Sci Biotech 5: 12-19.

Grouzis M. 1973. Exigences écologiques compares d'une salicorne vivace et d'une salicorne annuelle; germination et croissance des stades jeunes. Oecolog Plant 8: 36-375.

Grouzis M, Heim G, Berger A. 1977. Croissance et accumulation des sels chez deux salicornes annuelles du littoral mediterranean. Oecolog Plant 12: 307-322.

Hanson AD, Scott NA. 1980. Betaine synthesis from radioactive precursors in attached, water stressed barley leaves. Plant Physiol 66: 342-348.

Hare PD, Cress WA. 1997. Metabolic implications of stress-induced proline accumulation in plants. Plant Growth Regul 21: 79-102.

Hekmat-Shoar H. 1978. Analyse des relations phylogéniques entre trois Suaeda par culture en milieu diversement salés. B Soc Bot Fr 125: 293-306.

Jefferies RL, Rudmik T, Dillon EM. 1979. Responses of halophytes to high salinities and low water potentials. Plant Physiol 64: 989-994.

Johnson D, Smith S, Dobrenz A. 1992. Genetic and phenotypic relationships in response to $\mathrm{NaCl}$ at different developmental stages in alfalfa. Theor Appl Genet 83: 833-838.

Kadereit G, Ball P, Beer S, Mucina L, Sokoloff D, Teege P, Yaprak AE, Freitag H. 2007. A taxonomic nightmare comes true: phylogeny and biogeography of glassworts (Salicornia L., Chenopodiaceae). Taxon 56:1143-1170.

Katschnig D, Broekman R, Rozema J. 2013. Salt tolerance in the halophyte Salicornia dolichostachya Moss: growth, morphology and physiology. Environ Exp Bot 92: 32-42.

Khan MA, Ungar IA, Showalter AM, Dewald HD. 1998. NaCl-induced accumulation of glycinebetaine in four subtropical halophytes from Pakistan. Physiol Plant 120: $487-$ 492.

Khan MA, Ungar IA, Showalter AM. 2000. The effect of the salinity on the growth, water status, and ion content of a leaf succulent perennial halophyte, Suaeda fruticosa (L) Forssk. J Arid Environ 45: 73-84. 
Königshofer H. 1983. Changes in ion composition and hexitol content of different Plantago species under the influence of salt stress. Plant Soil 72: 289-296.

Koyro HW 2006. Effect on salinity on growth, photosynthesis, water relations and solute composition of the potential cash crop halophyte Plantago coronopus (L.). Environ Exp Bot 56: 136-146.

Ksouri R, Megdiche W, Koyro H, Abdelly C. 2010. Responses of halophytes to environmental stresses with special emphasis to salinity. Adv Bot Res 53: 117-145.

Lauchli A, Epstein E.1990. Plant responses to saline and sodic conditions. In: Tanji KK .editor. Agricultural salinity assessment and management. New York: American Society of Civil Engineering. pp113-137.

Munns R. 2002. Comparative physiology of salt and water stress. Plant Cell Environ 25: 239250.

Munns R, Tester M. 2008. Mechanisms of salinity tolerance. Ann Rev Plant Biol 59: 651-681.

Naidoo GR, Rughunanan R. 1990. Salt tolerance in the succulent halophyte, Sarcocornia natalensis. J Exp Bot 41:497-502.

Nawaz K, Ashraf M. 2010. Exogenous application of glycinebetaine modulates activities of antioxidants in maize plants subjected to salt stress. J Agron Crop Sci 196: 28-37.

Pacurar A, Al Hassan M, Gaspar A, Boscaiu M, Vicente O. 2013. Stress-induced accumulation of osmoprotectants in four Plantago species. Bull UASMV Hort 70: 255-256.

Rhodes D, Hanson AD. 1993. Quaternary ammonium and tertiary sulfonium compounds in higher-plants. Annu Rev Plant Physiol Mol Biol 44:357-384.

Rivas-Martínez S, Rivas-Sáenz S. 2009. Worldwide Bioclimatic Classification System. Phytosociological Research Center Complutense University of Madrid, Spain. http://www.globalbioclimatics.org/. Accessed 11 Dec 2013.

Robinson SP, Jones GP. 1986. Accumulation of glycine betaine in chloroplasts provides osmotic adjustment during salt stress. Aust J Plant Physiol 13: 659-668.

Rozema J, Flowers T. 2008. Crops for a salinized world. Science 322: 1478-1480.

Saradhi P, Alia P, Arora S, Prasad KV. 1995. Proline accumulates in plants exposed to UV radiation and protects them against UV induced peroxidation. Biochem Biophys Res Commun 209: 1-5.

Siripornadulsil S, Train S, Verma DPS, Sayre RT. 2002. Molecular mechanisms of proline mediated tolerance to toxic heavy metals in transgenic microalgae. Plant Cell 14: 2837 2847.

Smirnoff N, Cumbes QJ. 1989. Hydroxyl radical scavenging activity of compatible solutes. Phytochemistry 28: 1057-1060.

Stewart GR, Lee JA. 1974. The role of proline accumulation in halophytes. Planta 120: 279289 . 
Szabados L, Savouré A. 2010. Proline: a multifunctional amino acid. Trends Plant Sci 15:8997.

Türkan I, Demiral T.2009. Recent developments in understanding salinity tolerance. Environ Exp Bot 67: 2-9.

Verbruggen N, Hermans C. 2008. Proline accumulation in plants: a review. Amino Acids 35:753-759.

Vicente O, Boscaiu M, Naranjo MA, Estrelles E, Bellés JM, Soriano P. 2004. Responses to salt stress in the halophyte Plantago crassifolia (Plantaginaceae). J Arid Environ 58: 463481.

Williams MD, Ungar IA. 1972. The effect of environmental parameters on the germination, growth, and development of Suaeda depressa .Pursh. Wats. Am J Bot 59: 912-918.

Xing L, Cai M, Chen S, Chen L, Lan H. 2013. Seed germination, plant growth and physiological responses of Salsola ikonnikovii to short-term $\mathrm{NaCl}$ stress. Plant Biosyst 147: 285-297.

Yeo AR, Flowers T J. 1980. Salt tolerance in the halophyte Suaeda maritima L. Dum.: Evaluation of the effect of salinity upon growth. J Exp Bot 31: 1171-1183.

Zhu J-K. 2001. Plant salt tolerance. Trends Plant Sci 6: 66-71. 


\section{Figure legends}

Fig. 1. Electric conductivity (means $\pm \mathrm{SD}, \mathrm{n}=5$ ) measured in aqueous soil extracts at a soil-towater ratio of 1: $1(\mathrm{w} / \mathrm{v})\left(\mathrm{EC}_{1: 1}\right)$ in the sampling area of $P$. crassifolia and I. crithmoides (a), and in pots after 2-month $\mathrm{NaCl}$ treatments in the growth chamber (b).

Fig. 2Proline (a, c) and glycine betaine (b, d) contents in the Plantago crassifolia (black bars) and Inula crithmoides (white bars) plants sampled in their natural habitats (means \pm SD, $n=5$ ) in the indicated seasons over 2 successive years. Different lower case letters indicate significant differences between samplings $(\alpha=0.05)$

Fig. 3 Growth responses to the 2-month saline treatments with the indicated $\mathrm{NaCl}$ concentrations under controlled conditions in Plantago crassifolia (black bars) and Inula crithmoides (white bars) (means $\pm \mathrm{SD}, \mathrm{n}=10$ ). Length of the longest leaf in P. crassifolia and of the stem in I. Crithmoides (a), and fresh weight of both species (b) were calculated in relation to the mean value of the non-treated controls, which was considered $100 \%$ ( $25.5 \mathrm{~cm}$ length of the longest leaf and $927 \mathrm{mg}$ fresh weight in P. crassifolia; $18.6 \mathrm{~cm}$ length of the stem and 579 mg fresh weight in I. crithmoides). Different lower case letters, Latin for P. crassifolia and Greek for I. crithmoides, indicate significant differences between treatments; asterisks indicate significant differences between the two species for a given $\mathrm{NaCl}$ concentration $(\alpha=0.05)$.

Fig. 4Proline ( $a, c)$ and glycine betaine (b, d) accumulation upon salt stress treatments in the Plantago crassifolia (black bars) and Inula crithmoides (white bars) plants treated for 2 months with the indicated $\mathrm{NaCl}$ concentrations (means $\pm \mathrm{SD}, \mathrm{n}=5$ ). Different lower case letters, Latin for P. crassifolia and Greek for Inula crithmoides, indicate significant differences between treatments $(\alpha=0.05)$. 
Table 1. Climate data in the sampling area of P. crassifolia and I. crithmoides. Average temperature values (Av. T) correspond to the means $( \pm \mathrm{SD})$ of weekly data during the two months previous to the sampling day $(\mathrm{n}=8)$. Precipitation $(\mathrm{P})$ and evapotranspiration (ETP) are accumulated values of weekly data for the same period. Data provided by the Agroclimatic Information System for Irrigation (SIAR) of the Spanish Ministry of Environment, Rural and Marine Affairs (MARM).

\begin{tabular}{|c|c|c|c|}
\hline & Mean $\pm S^{1}$ & Accumulated & (2 month) \\
\hline Sampling season & Av. T $\left({ }^{\circ} \mathbf{C}\right)$ & $\mathbf{P}(\mathbf{m m})$ & $\operatorname{ETP}(\mathbf{m m})$ \\
\hline Spring 2009 & $12.71 \pm 1.63 \mathrm{~d}$ & 116.80 & 155.49 \\
\hline Summer 2009 & $21.88 \pm 2.39 \mathrm{ab}$ & 8.40 & 286.77 \\
\hline Autumn 2009 & $19.29 \pm 1.79 b$ & 324.80 & 143.46 \\
\hline Spring 2010 & $12.07 \pm 2.90 \mathrm{~d}$ & 113.00 & 136.95 \\
\hline Summer 2010 & $22.41 \pm 2.58 \mathrm{a}$ & 55.00 & 285.90 \\
\hline Autumn 2010 & $14.67 \pm 2.96 c$ & 75.80 & 119.88 \\
\hline
\end{tabular}

${ }^{1}$ Numbers followed by the same letter are not significantly different $(\mathrm{P}>0.05$; ANOVA followed by Tukey test) 


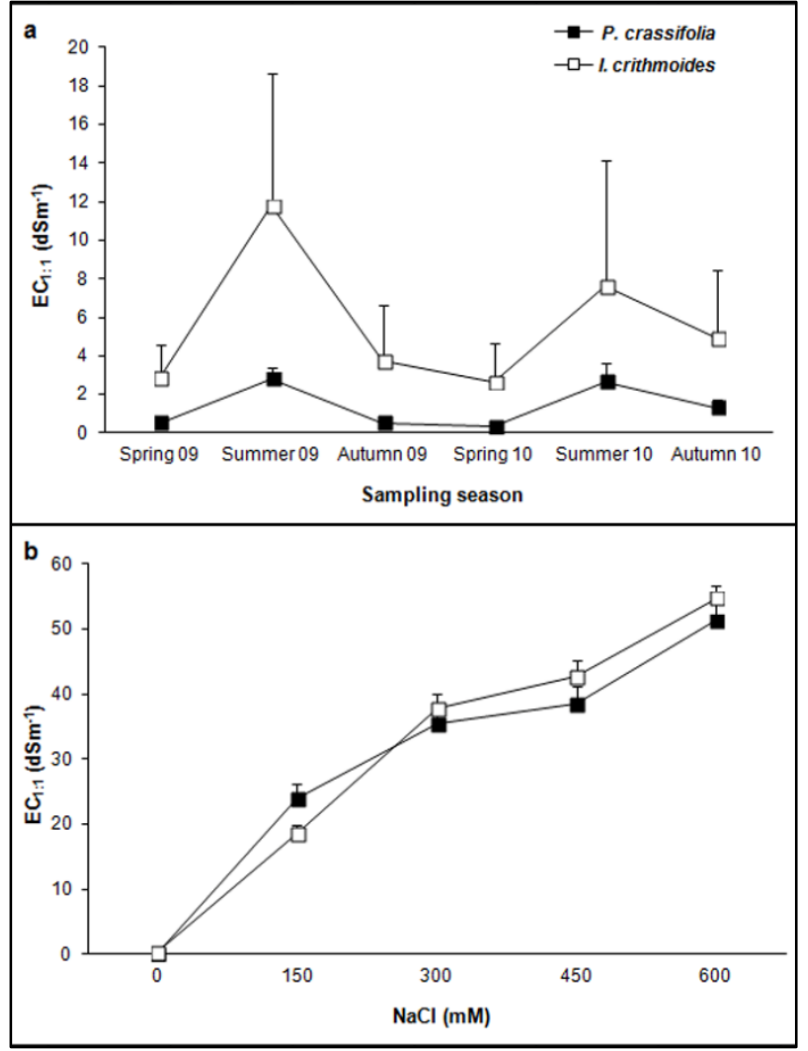

Fig. 1

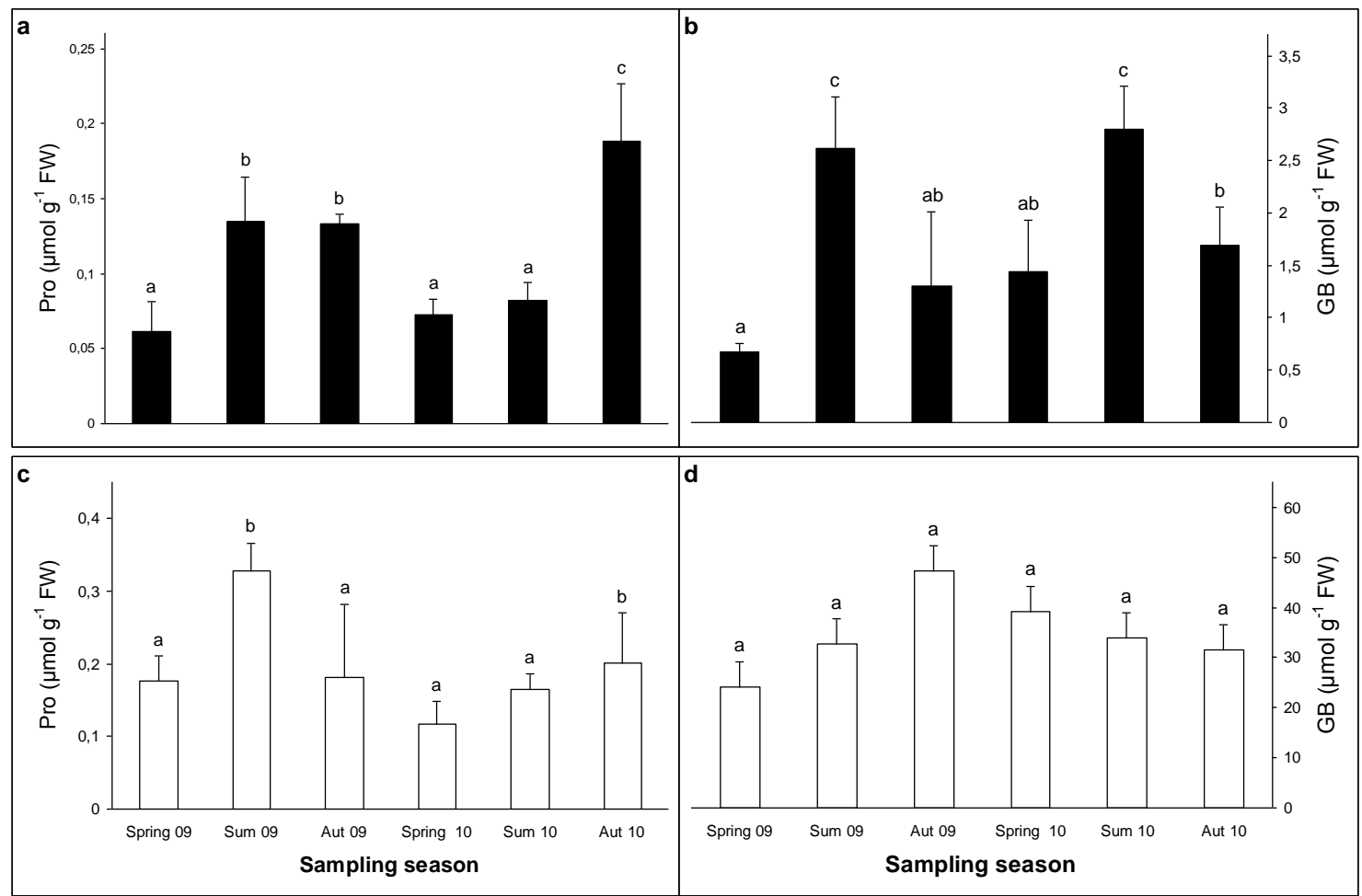

Fig. 2 

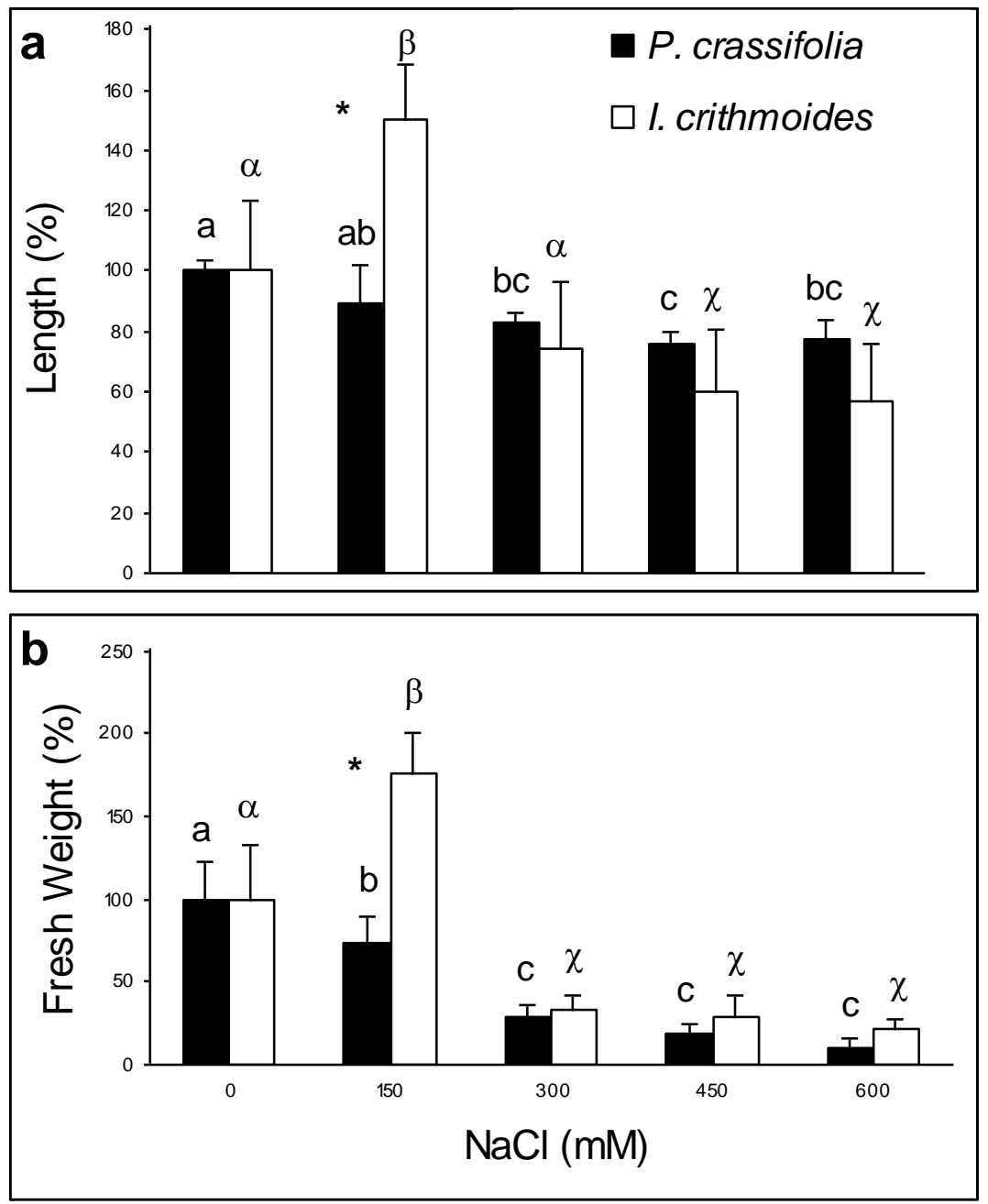

Fig. 3

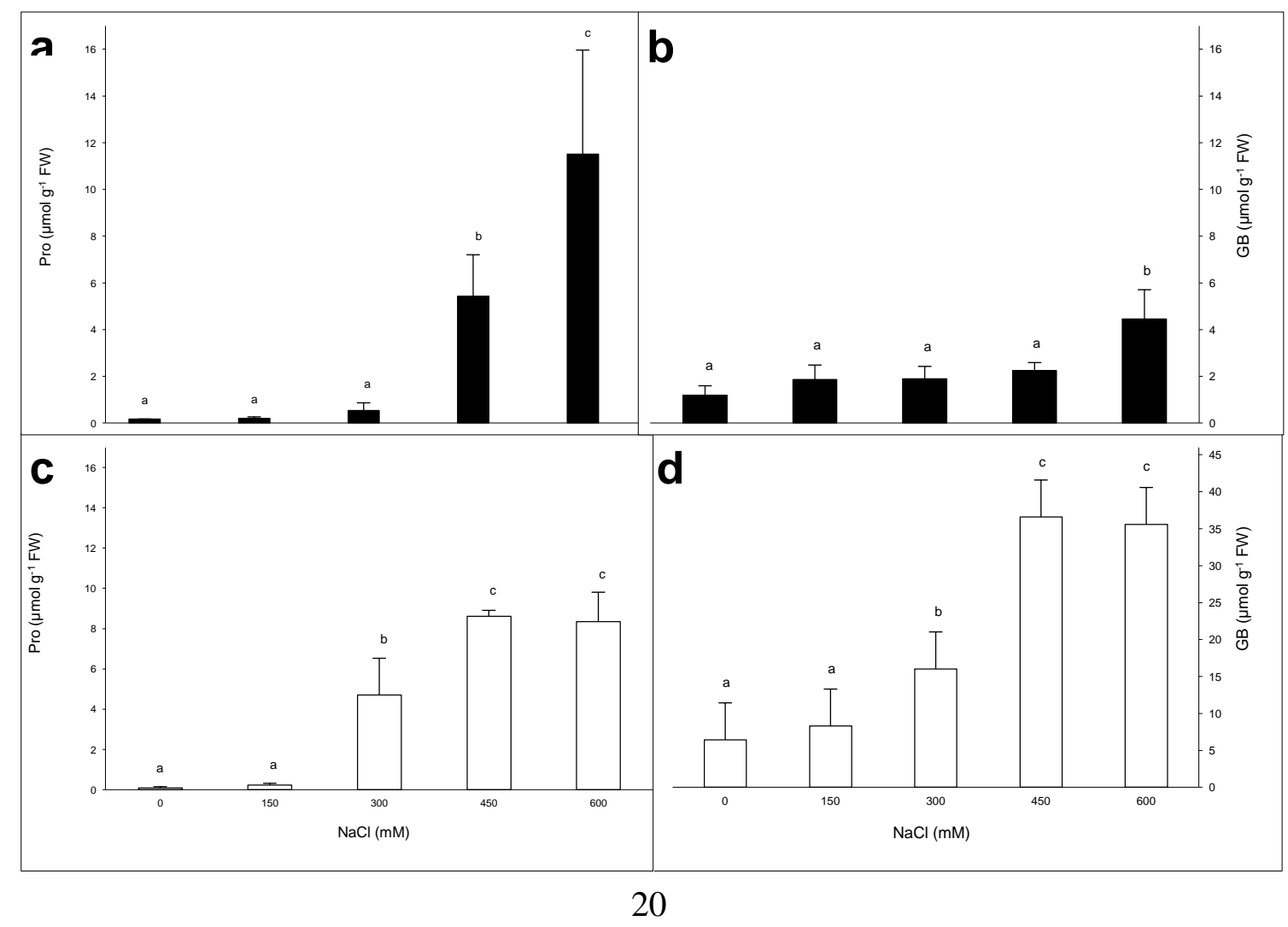

